\title{
Saharan dust levels in Greece and received inhalation doses
}

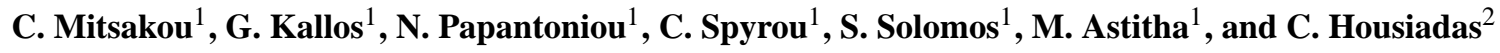 \\ ${ }^{1}$ National and Kapodistrian University of Athens, Department of Physics, Athens, Greece \\ ${ }^{2}$ National Centre for Scientific Research "Demokritos", Inst. of Nuclear Technology and Radiation Protection, Athens, Greece
}

Received: 7 March 2008 - Published in Atmos. Chem. Phys. Discuss.: 16 June 2008

Revised: 29 October 2008 - Accepted: 31 October 2008 - Published: 9 December 2008

\begin{abstract}
The desert of Sahara is one of the major sources of mineral dust on Earth, producing around $2 \times 10^{8}$ tons/yr. Under certain weather conditions, dust particles from Saharan desert get transported over the Mediterranean Sea and most of Europe. The limiting values set by the directive EC/30/1999 of European Union can easily be exceeded by the transport of desert dust particles in the south European Region and especially in urban areas, where there is also significant contribution from anthropogenic sources. In this study, the effects of dust transport on air quality in several Greek urban areas are quantified. $\mathrm{PM}_{10}$ concentration values from stationary monitoring stations are compared to dust concentrations for the 4-year period 2003-2006. The dust concentration values in the Greek areas were estimated by the SKIRON modelling system coupled with embedded algorithms describing the dust cycle. The mean annual dust contribution to daily-averaged $\mathrm{PM}_{10}$ concentration values was found to be around or even greater than $10 \%$ in the urban areas throughout the years examined. Natural dust transport may contribute by more than $20 \%$ to the annual number of exceedances - $\mathrm{PM}_{10}$ values greater than EU limits depending on the specific monitoring location. In a second stage of the study, the inhaled lung dose received by the residents in various Greek locations is calculated. The particle deposition efficiency of mineral dust at the different parts of the human respiratory tract is determined by applying a lung dosimetry numerical model, which incorporates inhalation dynamics and aerosol physical processes. The inhalation dose from mineral dust particles was greater in the upper respiratory system (extrathoracic region) and less significant in the lungs, especially in the sensitive alveolar region. However, in cases of dust episodes, the amounts of mineral dust deposited along the human lung are comparable to those received during exposure in heavily polluted urban or smoking areas.
\end{abstract}

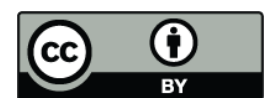

Correspondence to: G. Kallos (kallos@mg.uoa.gr)

\section{Introduction}

Mineral dust, produced by wind erosion, over arid and semiarid areas of North Africa, is transported over the Mediterranean Sea and most of Europe, under certain weather conditions. Desert dust particles affect the atmosphere and climate. By scattering and absorbing solar radiation they modify the planetary albedo and reduce the amount of radiation reaching the Earth's surface (Yu et al., 2001). Aerosols act as cloud condensation nuclei $(\mathrm{CCN})$, thus modifying the microphysical, micro-chemical and, hence, optical and radiative properties of clouds (Charlson et al., 1991). They can also influence the nutrient dynamics and biogeochemical cycling of both terrestrial and oceanic ecosystems (Herut et al., 2001).

In the past decades, several studies indicated a clear connection between suspended particulate matter and health effects (Dockery and Pope, 1994). Therefore, the European Community has established the Air Quality Directive 1999/30/EC limiting the concentration levels of $\mathrm{PM}_{10}$; mean annual $\mathrm{PM}_{10}$ concentrations should not exceed $40 \mu \mathrm{g} \mathrm{m}^{-3}$, and the daily limit value of $50 \mu \mathrm{g} \mathrm{m}^{-3}$ should not be exceeded more than 35 days/yr. The above standards had to be accomplished by the year 2005 . These limiting values can easily be exceeded by naturally produced aerosols (desert dust) for many days during the year in all southern European areas and especially in urban locations, where the contribution from anthropogenic sources is always considerable. Thus, many recent studies have focused on the estimation of the influence of the African dust on air quality in southern European countries and especially in Spain and Italy (Querol et al., 2001; Rodríguez et al., 2003; Escudero et al., 2007; Perrino et al., 2008). A recent analysis of Kallos et al. (2007a) and Astitha et al. (2008) showed that for approximately $50 \%$ of the days with daily $\mathrm{PM}_{10}$ exceedance there is desert dust contribution, small or large (analysis for the period 2001-2005).

Published by Copernicus Publications on behalf of the European Geosciences Union. 
The first objective of this study is to quantify the effects of dust transport on air quality in several Greek urban areas using a large number of data from PM monitoring stations and air quality model outputs. The model used is the SKIRON weather forecasting system with the desert dust module (Kallos et al., 1997; Nickovic et al., 2001). The second objective is to investigate the inhaled doses of dust received by the residents in the Greek urban areas during various exposure conditions. Inhaled dust particles may be deposited at different parts of the human respiratory tract (nasopharyngeal, tracheobronchial, alveolar region). The determination of the particle deposition at different parts of the respiratory system is an essential step in investigating possible risks from exposure to desert dust. To this end, a recently developed dosimetry model (Mitsakou et al., 2005) is applied. The model calculates deposited inhaled aerosols in the various regions of the human respiratory tract, taking into account the aerosol properties (e.g. size distribution, hygroscopicity) and the physiological conditions of the individual.

The methodology adopted for the air quality and dosimetry analyses is described in Sect. 2, while Sect. 3 provides discussion of the results. Finally, the concluding remarks of the study are summarized in Sect. 4.

\section{Methodology}

\subsection{Air quality analysis}

For the purpose of this study, the operational runs of the SKIRON system and the daily-averaged $\mathrm{PM}_{10}$ mass concentration measurements from air quality monitoring stations of the Greek Ministry of Environment City Planning and Public Works (MECPPW) have been analyzed. Correlations between the model outputs and the $\mathrm{PM}_{10}$ measurements from the monitoring stations can help identifying the dust contribution to the air quality in the Greek urban areas. The model predictions and the experimental measurements cover the four-year period of 2003-2006. A brief description of the implemented tools is given below.

\subsubsection{SKIRON modelling system}

In this study, the SKIRON atmospheric modelling system was used (Kallos et al., 1997; Papadopoulos et al., 2002). SKIRON is a modified version of the Eta/NCEP regional atmospheric model, fully coupled with a module for describing the desert dust cycle in the atmosphere. The Eta model is well-documented and detailed descriptions of its dynamical and physical components can be found in several studies (e.g., Mesinger et al., 1988; Janjic, 1994, and references therein). This initial version has been further improved by incorporating high resolution sea surface temperature SST fields, spatial distributions of clay amounts, non-hydrostatic corrections, as suggested by Janjic et al. (2001), in-cloud deposition efficiency, etc. During the SKIRON and POSEI-
DON projects, the atmospheric radiation and surface processes have been tested and updated (Papadopoulos et al., 2002).

The first dust cycle module was developed at the University of Athens in the framework of the MEDUSE project and further tested and developed during the ADIOS project. In Nickovic et al. (2001), it was given the name DREAM (Dust REgional Atmospheric Model). The present version incorporates several state-of-the-art parameterizations for the description of the production, transport and removal processes of the desert dust cycle, while several inconsistencies in the initial version described in Nickovic et al. (2001) have been corrected. For the definition of the areas that are potentially active, global datasets are used for the vegetation (Olson World Ecosystems with $30 \times 30$ resolution) and soil texture (FAO/UNESCO with $2 \times 2$ resolution). The soil texture dataset has been enhanced by using the concept of rocky soil. Also, the soil moisture and turbulent state of the atmosphere play a critical role in the amount of dust uplifted and injected into the air. Since the dust cycle module is dynamically coupled to the atmospheric model, the prognostic atmospheric and hydrological conditions are used to calculate the effective rates of the injected dust at each time step.

The initial version was using a single particle size (19972003). The model version used in the present study had four size bins with centered diameters of $1.5,12,36$, and $76 \mu \mathrm{m}$ (Tegen and Fung, 1994). For the present analysis, the model outputs that correspond to the two smaller-diameter (1.5 and $12 \mu \mathrm{m})$ size bins are taken into account in order to approach the $\mathrm{PM}_{10}$ African dust. The ability of the model to predict the dust concentration for a long period has been tested for long-range transport of Saharan dust across the Atlantic Ocean (Kallos et al., 2006). The simulated dust concentration values appeared to agree satisfactorily with the available observations. Moreover, the evaluation of dust transport simulations with the SKIRON system proceeded with the aid of ground dust concentration measurements in Haifa, Israel and LIDAR measurements performed from 2001 to 2003 in Rome, Italy. More details on the evaluation of the system can be found in the works of Kishcha et al. (2007) and Kallos et al. (2007b). In addition, the various versions of SKIRON (also known as DREAM) model have been widely applied for the determination of African dust production, transport and deposition in the last years with satisfactory predictions (Rodríguez et al., 2001; Rodríguez et al., 2003; Viana et al., 2005; Astitha et al., 2008; Papayannis et al., 2008).

The SKIRON system with the dust component has been in operational use at the University of Athens since 1998, providing 72-h weather and dust transport and deposition forecasts for the Mediterranean region. These forecasts are available from the Internet site http://forecast.uoa.gr/, while the systematic backup is executed since the beginning of 2000 . After 2003, the four-size distribution version with the corrections mentioned above is set up in operational use. Recently, a newest version with eight size bins, as proposed by Zender 
et al. (2003), together with several other improvements has replaced the operational one. In the present work, the long time series of desert dust data with four size bins are used to quantify the effects of naturally produced aerosols in $\mathrm{PM}_{10}$ monitoring stations in Greece.

\subsubsection{Experimental data}

The MECPPW has a relatively dense monitoring network in Athens and in major Greek urban areas. However, in many of them there are long gaps in the monitoring procedure. Thus, four monitoring sites were selected for the present analysis based on the data availability and geographical location. The selection criteria were related to the length of the time series, the location of the stations and the representativeness of the greater urban conglomerate. Each monitoring station is situated in populated Greek urban areas, namely, Athens, Patra, Volos, Heraklion. The locations of the monitoring stations are displayed in Fig. 1. According to the criteria proposed by the European Environment Agency, the monitoring station of Athens located northwest of the city center (Thrakomakedones) is a suburban-background station. Thus, the contribution of local PM sources (traffic, construction works and other anthropogenic activities) to air quality at the specific area is limited and the contribution of the natural sources is more easily detectable. However, no suburban monitoring stations have been placed in the other urban areas (Patra, Volos, Heraklion). These cities are relatively small (150 000-300 000 inhabitants) and therefore, the analysis was conducted with the data collected from the urban monitoring stations of the three areas. The concentration of $\mathrm{PM}_{10}$ aerosol particles is monitored at the above-mentioned sites by using $\beta$-attenuation systems.

\subsubsection{SKIRON output processing}

The forecast model generates hourly dust concentrations. Thus, the daily-averaged values of dust concentration had to be calculated based on the hourly values for the comparison with the experimental ones from the monitoring stations. The model domain covers the area from $24^{\circ} \mathrm{W}$ to $41^{\circ} \mathrm{E}$ and from $9^{\circ} \mathrm{N}$ to $60^{\circ} \mathrm{N}$. The horizontal grid increment of the model domain is $0.24^{\circ}$ (approximately $25 \mathrm{~km}$ ). In the vertical, $32 \mathrm{lev}$ els were used stretching from the ground to the model top $(20 \mathrm{~km})$. The determination of the simulated dust concentration at the specific measuring points of the MECPPW stations was achieved by applying linear interpolation to the model outputs. More specifically, the aerosol concentration at the measuring points was approximated by the relative contribution of the closest grid points of SKIRON domain introducing a weight function (inverse distance weighting) for the contribution of the grid points to the actual location of the MECPPW station.

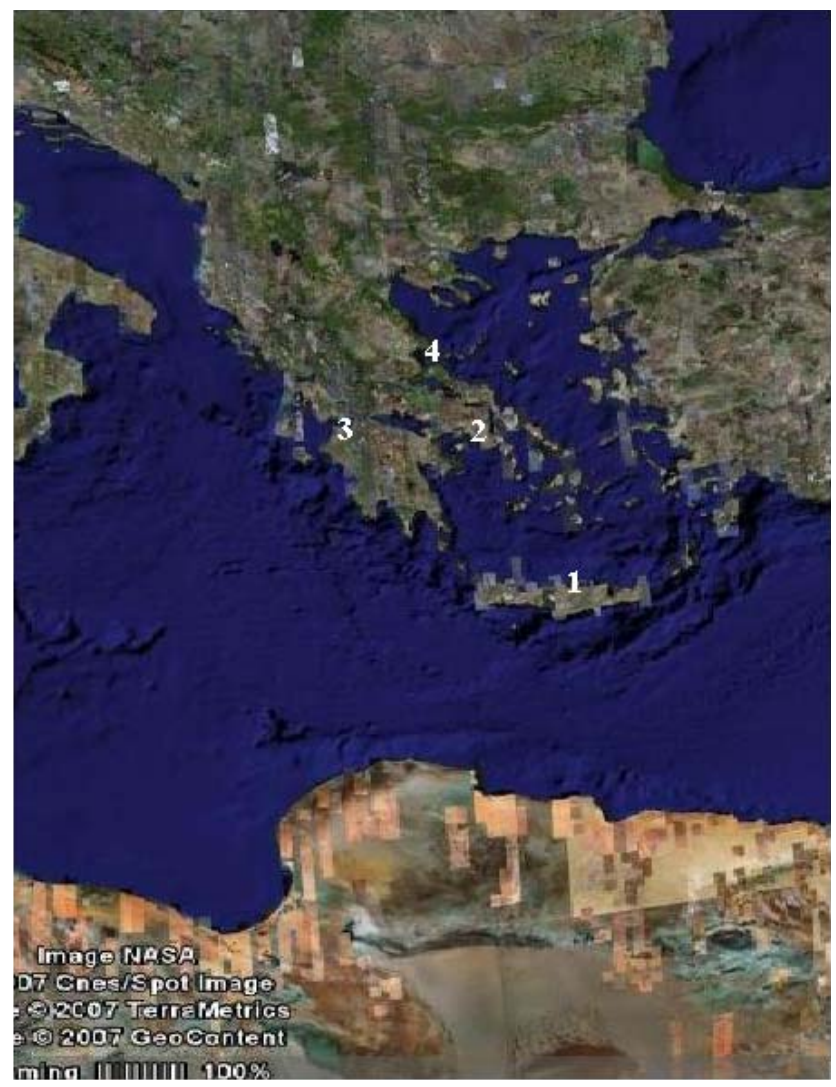

Fig. 1. Location of the Greek monitoring stations, 1: Heraklion, 2: Athens suburb, 3: Patra, 4: Volos. (Source: www.googleearth. com).

\subsection{Dosimetry analysis}

For the dosimetric calculations a mechanistic inhalation dosimetry model is used, which includes both inhalation and aerosol dynamics (Mitsakou et al., 2005). The model solves the aerosol general dynamic equation (GDE) along the flow direction (in one dimension). The size distribution is described with a sectional representation, which allows for arbitrary functional forms of the size distribution. The description of the respiratory tract is based on Weibel's morphometric model "A" (Weibel, 1963), incorporating time-varying alveolar region during breathing (expanding and contracting rhythmically during respiration). The particle deposition is assumed to be the result of the mechanisms of gravitational settling, Brownian diffusion and inertial impaction, acting simultaneously. The air velocity in the airways is determined by solving the equation of continuity.

The deposition rate of inhaled particles in the respiratory tract is calculated by summing up the calculated rate for each size bin, taking into account the tidal volume (volume of air inspired and expired during each respiratory cycle) and the breathing frequency (number of breaths per time), as follows

Deposition rate $=\sum_{i} D F_{i} \cdot n_{i} \cdot V_{T} \cdot f$ 

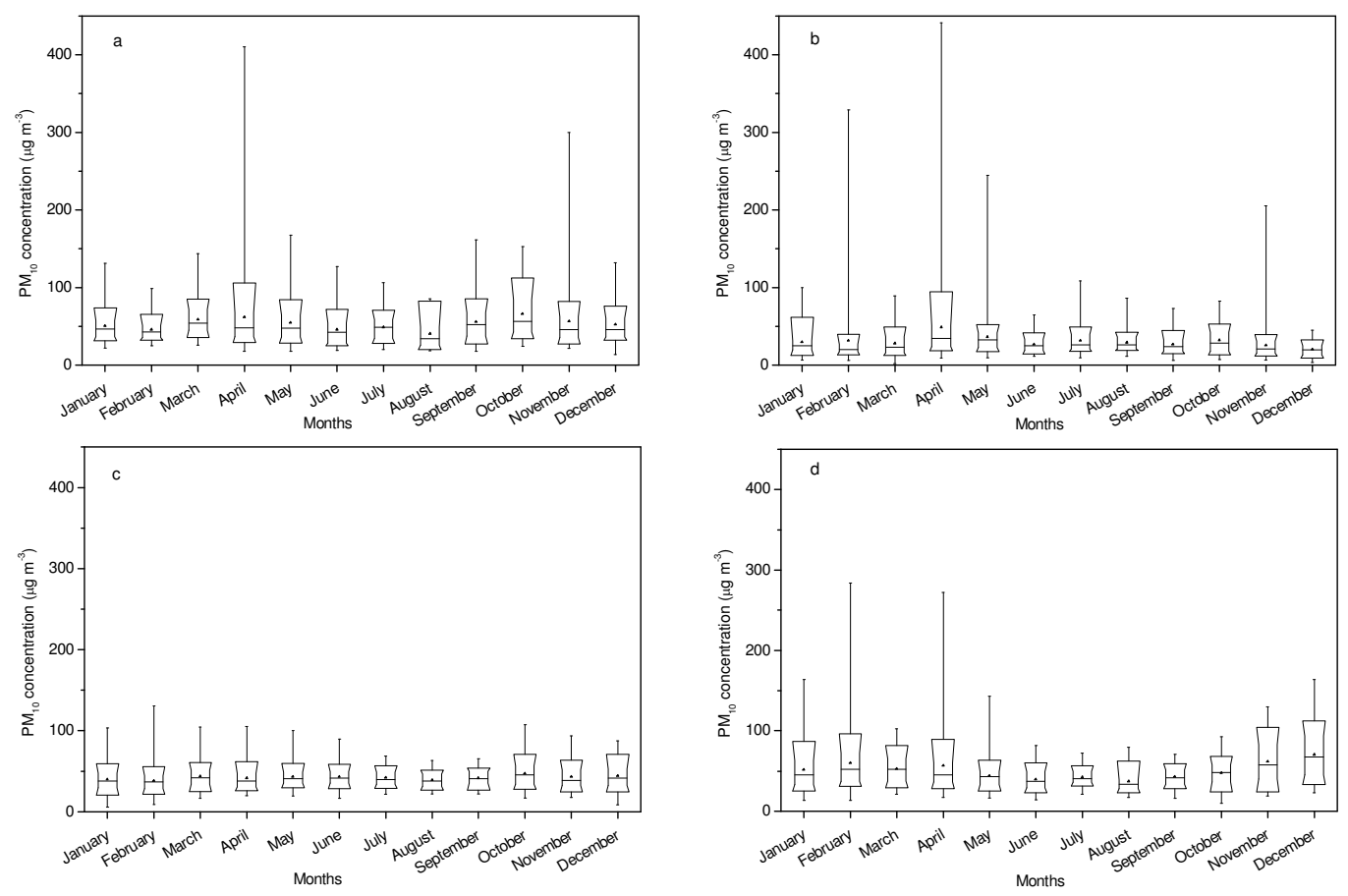

Fig. 2. Box plots of $\mathrm{PM}_{10}$ concentration values for the sites of (a) Heraklion, (b) Athens suburb, (c) Patra, (d) Volos, for the period 20032006 (for Heraklion 3-year period: 2003-2005). Upper and lower bars indicate 90th and 10th percentiles, the bars and the markers inside the boxes indicate the median and the mean values respectively and the whiskers range between minimum and maximum values.

where $D F$ is the calculated deposited fraction, $n_{i}$ the particle number concentration of the $i$ th size section at the entrance of the respiratory tract, $V_{T}$ the tidal volume and $f$ the breathing frequency. The physiological parameters $V_{T}$ and $f$ depend on the level of physical exertion. The values utilized in our calculations are taken from ICRP (1994), as recommended for an adult Caucasian male under the typified conditions of light exercise $\left(V_{T}=1250 \mathrm{ml}, f=20 \mathrm{~min}^{-1}\right)$.

\section{Results and discussions}

\subsection{Natural dust transport}

A first approach for the origin of the urban particulate matter is attempted via a statistical analysis of the $\mathrm{PM}_{10}$ concentration values from the monitoring stations. The box plots in Fig. 2a-d illustrate the statistical parameters (minimum/maximum, mean, median values, 10th and 90th percentiles) of the monthly concentration of $\mathrm{PM}_{10}$ measurements for each monitoring station. These values were calculated from the measured concentrations obtained during the respective months of the 4-year database (3-year database for Heraklion, measurements for 2006 are missing).

Peak $\mathrm{PM}_{10}$ values can be identified mostly during the transition seasons (spring and autumn) and secondarily in winter in almost all monitoring sites, while minimum values are usually noticed during the summer period due to the prevailing northerly wind patterns (etesian winds, see Kallos et al., 1993). For example, the monthly averaged $\mathrm{PM}_{10}$ concentrations for the Athens suburban station have maximum in April, when African dust concentrations are also high (see Figs. 2, 3). Maximum $\mathrm{PM}_{10}$ concentration values exceed $400 \mu \mathrm{g} \mathrm{m}^{-3}$ during April in Athens and Heraklion. The most significant sources of $\mathrm{PM}_{10}$ could be natural (Saharan dust, sea salt, pollen from pine and olive trees during spring), but also anthropogenic (central heating, traffic, industry), as mentioned in previous studies (e.g. Querol et al., 2004). The maximum sea salt concentration occurs during the winter period due to the high sea spray production (Koçak et al., 2007). Moreover, the use of central heating reaches a peak load during winter. Increased dust transport takes place in the transition seasons (spring and autumn, Gerasopoulos et al., 2006; Kallos et al., 2007b). According to the above analysis, $\mathrm{PM}_{10}$ maximum values in spring or autumn months could be attributed mainly to mineral dust transport. It should be noted here, that there is accumulated contribution from local sources (e.g. traffic), but the seasonal variability is not considered as important as compared to dust amounts reaching the Greek areas during episodes. On the other hand, $\mathrm{PM}_{10}$ values in a town of approximately 150000 inhabitants in central Greece (Volos) show maximum aerosol concentrations in the winter period (December). Volos monitoring site is the most northern site compared to the other examined sites, 

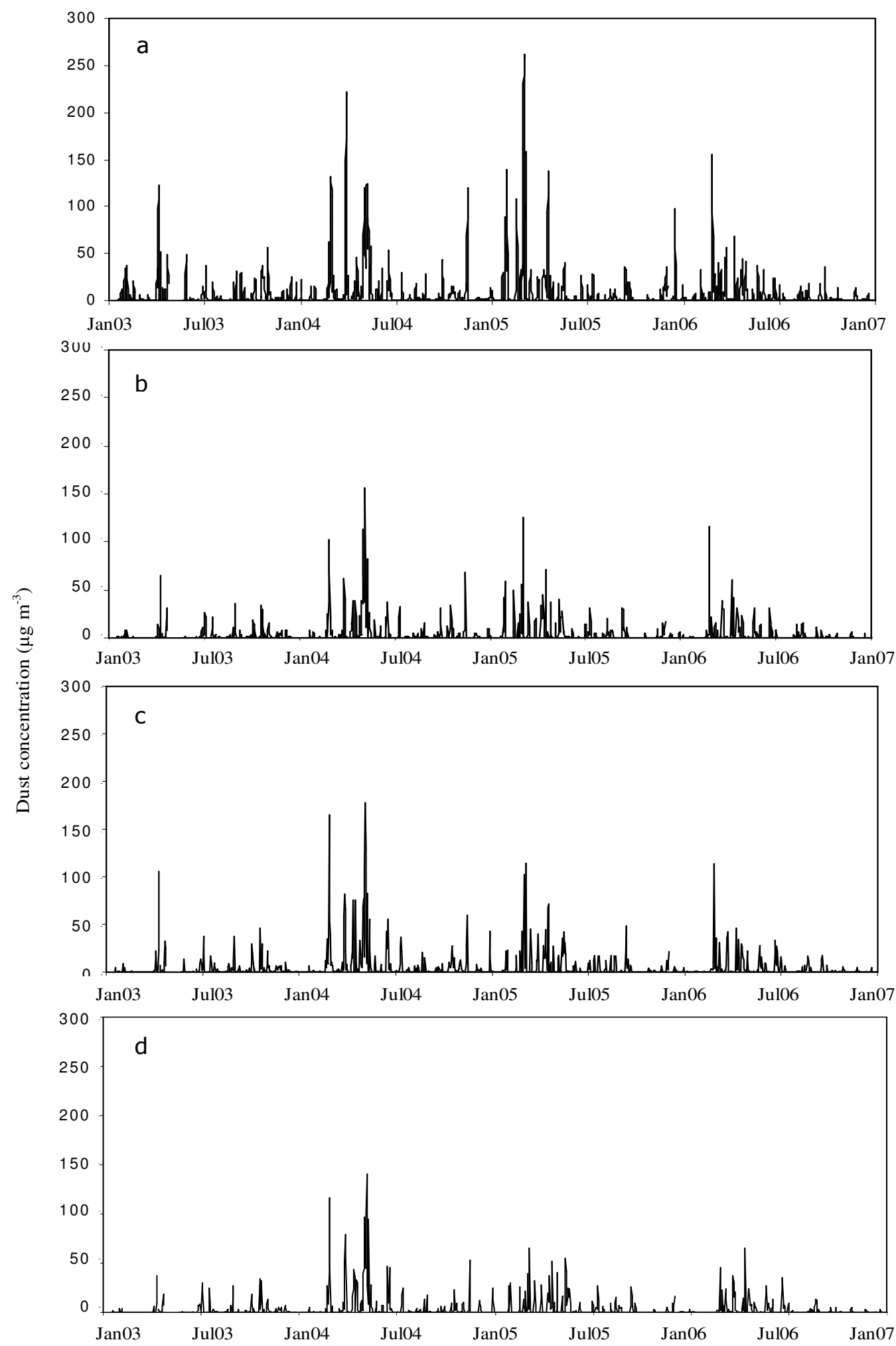

Fig. 3. Time-series of simulated dust concentrations for (a) Heraklion, (b) Athens suburb, (c) Patra, (d) Volos, during the period 2003-2006. 

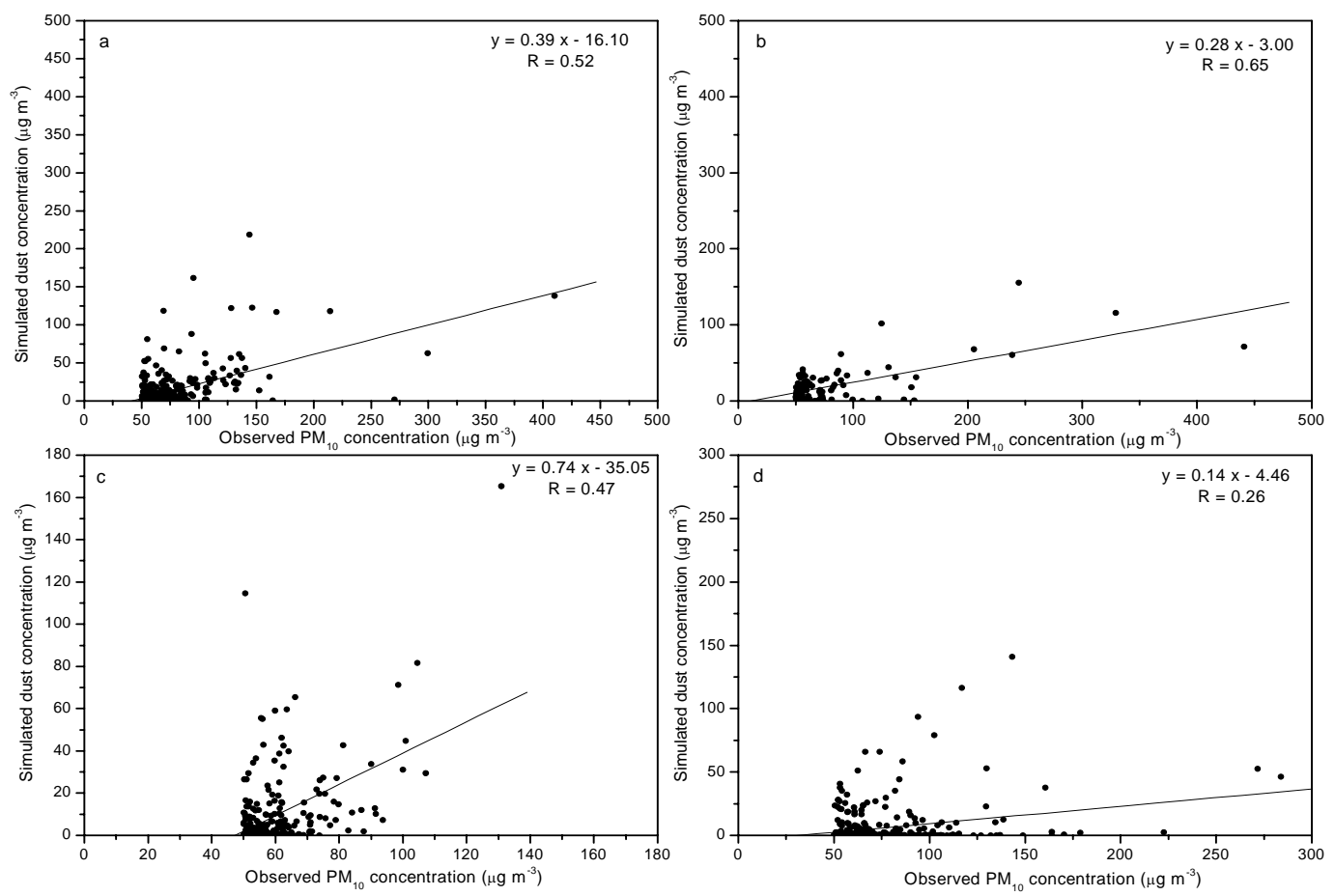

Fig. 4. Correlations between observed $\mathrm{PM}_{10}$ concentrations and simulated dust concentrations for the sites of (a) Heraklion, (b) Athens suburb, (c) Patra, (d) Volos, for the period 2003-2006 (for Heraklion 3-year period: 2003-2005).

the distance from Heraklion is approximately $4^{\circ}(\sim 400 \mathrm{~km})$. The influence of dust transport decreases towards higher geographical latitudes. The effect of dust transport is reduced with increasing distance from the dust source, as dust particles are deposited via wet and dry mechanisms along the transport paths. Thus, the contribution of dust particles to the air quality in Volos is expected to be limited, while there are other significant contributors to particle concentration in the area. Such contributors could be the two extended industrial areas at the outskirts of the town (one northwest of the town and a concrete production unit at the southeast part), where high PM amounts are released.

The periods of increased dust transport are also distinguished by the simulated dust concentration values. In Fig. 3, the time series of Saharan dust levels for the four urban areas, as simulated by the SKIRON modelling system, are illustrated for the period 2003-2006. The most severe dust transport episodes usually appear during the period from the beginning of spring until the first days of June. Maximum values are noticed in May; high levels of dust concentration dominate in March and April. Secondary maxima of dust concentration can be identified during September and October. The above results appear to agree with the fact of increased dust concentrations during the transition periods.

Model estimates of near ground dust concentrations have been compared with $\mathrm{PM}_{10}$ observations. More specifically, in Fig. 4a-d scatter plots between predicted dust concen- trations and measured $\mathrm{PM}_{10}$ concentrations for the cases of daily exceedances (observed $\mathrm{PM}_{10}$ values greater than the daily EU limit of $50 \mu \mathrm{g} \mathrm{m}^{-3}$ ) are presented for each monitoring station and for the whole period (2003-2006). The seasonal trend lines of the scatter plots and the correlation coefficients for each season of the year separately and for each monitoring site are presented in Table 1, where $x$ is the observed $\mathrm{PM}_{10}$ concentration and $y$ is the simulated dust concentration (for cases of daily exceedances). The correlation coefficients appear to fluctuate between 0.78 (Heraklion, autumn period) and 0.26 (Volos). The low coefficient value between $\mathrm{PM}_{10}$ and dust concentrations for Volos station, during all seasons of the year, limits the statistical confidence of the estimation of dust contribution to the urban air quality for the specific area. This low correlation could be attributed to the geomorphological characteristics of the area, more specifically, the town is adjacent to a steep mountain that receives considerable amounts of precipitation and, thus, the washout effect becomes important. On the other hand, higher correlation values have been calculated for the southern site (Heraklion), especially during the transition autumn period. In general, the correlation between measured and simulated particle concentrations appears to be significantly weaker during the summer period in all sites, when dust transport from Saharan desert is limited due to the northerly etesian winds. Other factors responsible for the poor correlations could be the limitations of the atmospheric/dust transport model and 
Table 1. Seasonal trend lines and correlation coefficients between $\mathrm{PM}_{10}$ concentrations and simulated dust concentrations.

\begin{tabular}{ccccc}
\hline & Autumn & Winter & Spring & Summer \\
\hline Heraklion & $\mathrm{y}=0.37 \mathrm{x}-18.92, \mathrm{R}=0.78$ & $\mathrm{y}=0.21 \mathrm{x}-10.44, \mathrm{R}=0.59$ & $\mathrm{y}=0.39 \mathrm{x}-7.80, \mathrm{R}=0.46$ & $\mathrm{y}=0.19 \mathrm{x}-6.06, \mathrm{R}=0.28$ \\
Athens suburb & $\mathrm{y}=0.34 \mathrm{x}-9.01, \mathrm{R}=0.69$ & n. $\mathrm{a}^{*}$ & $\mathrm{y}=0.25 \mathrm{x}+0.86, \mathrm{R}=0.57$ & n.a \\
Patra & $\mathrm{y}=0.31 \mathrm{x}-12.42, \mathrm{R}=0.37$ & n.a & $\mathrm{y}=0.76 \mathrm{x}-30.44, \mathrm{R}=0.42$ & $\mathrm{y}=0.38 \mathrm{x}-14.62, \mathrm{R}=0.32$ \\
Volos & $\mathrm{y}=0.12 \mathrm{x}-5.15, \mathrm{R}=0.26$ & $\mathrm{y}=0.10 \mathrm{x}-5.27, \mathrm{R}=0.26$ & $\mathrm{y}=0.21 \mathrm{x}-2.93, \mathrm{R}=0.32$ & $\mathrm{y}=0.26 \mathrm{x}-12.03, \mathrm{R}=0.30$ \\
\hline
\end{tabular}

* not available, small number of available data

especially the global database used for the identification of dust sources (desert dust classification) and the relatively low horizontal resolution of the model $\left(0.24^{\circ} \times 0.24^{\circ}\right)$ that was the optimal choice of the operational runs given the wide model domain and the available computer resources.

The slope of the trend line in Fig. 4a-d is indicative of the percentage of mineral dust in $\mathrm{PM}_{10}$ concentration, when exceedances occur, while the intercept pertains to the urban background concentrations. For the monitoring station of Heraklion, the slope of the trend line is 0.39 (Fig. 4a) that denotes a dust contribution to urban aerosol approaching $40 \%$. Gerasopoulos et al. (2006) performed a chemical analysis of $\mathrm{PM}_{10}$ in combination with back-trajectories analysis for Heraklion during dust episodes. The analyses showed a participation of mineral dust at about $40 \%$ in $\mathrm{PM}_{10}$ daily exceedances throughout the year. Thus, the analysis of Gerasopoulos et al. (2006) seems to verify the dust contribution calculated in the present analysis. The fraction of dust transported particles to $\mathrm{PM}_{10}$ values exhibits the lowest value during the summer period (the slope of the trend line is 0.19 , see Table 1 ), which is in agreement with the findings of the latter work. The high intercept values for the site of Patra demonstrates the remarkable influence of local pollution, while the slope of 0.76 during the spring period reveals that dust transport also plays a significant role in the urban air quality. Dust transport seems to affect $\mathrm{PM}_{10}$ values in cases of daily exceedances in Athens by 25 and $34 \%$ during the spring and autumn periods respectively. However, a comparison with the other seasonal periods is not feasible due to very limited number of $\mathrm{PM}_{10}$ observations during winter and summer. It should be noted, though, that air quality in the Greek urban areas examined here is influenced by the introduction of sea-salt particles, as all the studied areas are near the seaside. Moreover, southwestern flows that enhance dust transport from the African continent, could also lead to severe air pollution episodes as they are combined with an abrupt temperature change (Kallos et al., 1993). Therefore, $\mathrm{PM}_{10}$ concentration data could not distinguish the dust transported mass from the other suspended materials. Note that the different correlations between simulated and observed values for the various urban areas should be also attributed to the different PM sources. More accurate predictions of dust contribution for the whole period are obtained for the monitoring site of Athens suburb (higher correlation coefficient in Fig. $4 \mathrm{~b}$ ), as the monitoring station there is characterized as suburban-background.

A more explicit statistical analysis of the observed and simulated data for the four years that we examined has been performed. Some of these results are summarized in Table 2. In this table, the values shown refer to the averaged observed and simulated values, the $\mathrm{PM}_{10}$ residual average concentrations (annual mean of daily $\mathrm{PM}_{10}$ levels after subtraction of dust concentrations), the dust contribution to averaged $\mathrm{PM}_{10}$ concentrations, the number of annual exceedances and the dust and the residual $\mathrm{PM}_{10}$ contribution to daily exceedances. The annual averaged dust concentration is determined by accounting all days and not only these with dust contribution to exceedances. The residual $\mathrm{PM}_{10}$ contribution was determined by re-calculating the number of exceedances after subtraction of dust simulated concentration values from the $\mathrm{PM}_{10}$ measured values and estimating the ratio of the new (after dust elimination) to the total number of exceedances. Thus, the dust contribution to exceedances is the supplementary fraction (100-residual $\mathrm{PM}_{10}$ contribution). By this approach, an exceedance is attributed to "non-African origin" if the residual of the subtraction of SKIRON dust load from the daily $\mathrm{PM}_{10}$ levels still exceeds the daily limit value, while the residual number of exceedances is attributed to an "African origin". The "non-African origin" exceedances are described by the last column in Table 2 and the "African origin" exceedances by the percentage of dust contribution to exceedances in the table (e.g. for Athens suburb during 2003, $65.7 \%$ of the daily exceedances were of "African origin" and $34.3 \%$ were of "non-African origin").

The monitoring site of Athens suburb shows the lowest aerosol concentration and number of exceedances comparing to the other sites; mass concentration for the suburbanbackground stations presents significantly lower values, since anthropogenic sources are less active in these areas. The annual averaged dust concentration decreases from the southern (Heraklion) towards the northern Greek site that we examined (Volos), according to SKIRON model predictions. As dust decreases, the $\mathrm{PM}_{10}$ residual average concentration tends to be equal to the $\mathrm{PM}_{10}$ average concentration. 
Table 2. $\mathrm{PM}_{10} / \mathrm{dust} / \mathrm{PM}_{10}$ residual average concentrations, number of annual exceedances and quantification of dust and $\mathrm{PM}_{10}$ residual contribution to urban air quality.

\begin{tabular}{|c|c|c|c|c|c|c|c|c|}
\hline Year & Stations & $\begin{array}{c}\mathrm{PM}_{10} \text { average } \\
\text { concentration } \\
\left(\mu \mathrm{g} \mathrm{m}^{-3}\right)\end{array}$ & $\begin{array}{l}\text { Dust average } \\
\text { concentration } \\
\left(\mu \mathrm{g} \mathrm{m}^{-3}\right)\end{array}$ & $\begin{array}{l}\mathrm{PM}_{10} \text { residual } \\
\text { average } \\
\text { concentration }\end{array}$ & $\begin{array}{l}\text { Dust contribution } \\
\text { to } \mathrm{PM}_{10} \\
\text { concentration } \\
(\%)\end{array}$ & $\begin{array}{c}\text { Annual } \\
\text { exceedances }\end{array}$ & $\begin{array}{c}\text { Dust } \\
\text { contribution to } \\
\text { exceedances } \\
(\%)\end{array}$ & $\begin{array}{c}\mathrm{PM}_{10} \text { residual } \\
\text { contribution to } \\
\text { exceedances } \\
(\%)\end{array}$ \\
\hline \multirow{4}{*}{2003} & Heraklion & 62.2 & 5.3 & 55.8 & 8.6 & 182 & 22.7 & 77.3 \\
\hline & Athens suburb & 31.7 & 2.4 & 27.4 & 7.6 & 35 & 65.7 & 34.3 \\
\hline & Patra & 44.8 & 3.1 & 41.1 & 6.9 & 113 & 30.6 & 69.4 \\
\hline & Volos & 49.0 & 1.9 & 45.8 & 4.0 & 97 & 25.0 & 75.0 \\
\hline \multirow{4}{*}{2004} & Heraklion & 56.9 & 9.3 & 47.2 & 16.1 & 140 & 22.2 & 77.8 \\
\hline & Athens suburb & 33.2 & 6.4 & 26.9 & 19.2 & 36 & 51.4 & 48.6 \\
\hline & Patra & 42.3 & 7.7 & 37.1 & 18.2 & 73 & 45.2 & 54.8 \\
\hline & Volos & 53.7 & 6.0 & 45.5 & 11.2 & 67 & 19.6 & 80.4 \\
\hline \multirow{4}{*}{2005} & Heraklion & 38.7 & 8.7 & 32.9 & 22.4 & $23^{*}$ & 47.8 & 52.2 \\
\hline & Athens suburb & 32.2 & 4.9 & 26.7 & 15.0 & 24 & 54.2 & 45.8 \\
\hline & Patra & 38.0 & 4.9 & 32.2 & 12.7 & 39 & 34.3 & 65.7 \\
\hline & Volos & 46.5 & 6.7 & 41.7 & 7.9 & 81 & 21.0 & 79.0 \\
\hline \multirow{3}{*}{2006} & Athens suburb & 27.0 & 3.1 & 23.4 & 11.3 & 10 & 30.0 & 70.0 \\
\hline & Patra & 42.9 & 3.2 & 38.5 & 7.4 & 29 & 31.0 & 69.0 \\
\hline & Volos & 55.0 & 2.4 & 53.6 & 4.3 & 121 & 5.8 & 94.2 \\
\hline
\end{tabular}

* small number of available data

In particular, the mineral dust concentration values at Volos appear to be about $30 \%$ lower than the dust concentration values predicted for the town of Heraklion for 2004 and 2005 (about 6 and $9 \mu \mathrm{g} \mathrm{m}^{-3}$ for Volos and Heraklion, respectively). The decreasing number of daily exceedances for the areas of Patra, Athens suburb and Heraklion ${ }^{1}$ during the 4year period can be attributed to a possible reduction of dust episodes, since mineral dust transport performs a significant inter-annual variation (e.g. Sunnu et al., 2008), while no particular reduction in anthropogenic PM emissions in Greece has been reported during the period analyzed. The dust contribution to $\mathrm{PM}_{10}$ concentrations - annual average of daily ratios of dust to $\mathrm{PM}_{10}$ concentrations - approaches and exceeds $10 \%$ for the areas of Patra, Athens suburb and Heraklion. In terms of daily exceedances the dust contribution is very high at the suburban station of Athens (e.g. 54.2\% for 2005) and noticeable for the other Greek urban areas $(>20 \%)$.

\subsection{Inhaled dose}

The human exposure to Saharan dust particles under various dust concentration levels is approached by calculating the different percentiles of aerosol concentration derived by SKIRON modelling system (Table 3 ). By determining the percentiles (90th, 95th, 99.5th, 100th), four exposure categories are distinguished for dust concentration values between the percentile intervals $(0-90,90-95,95-99.5,99.5-100)$. For

\footnotetext{
${ }^{1}$ Small number of available data for 2005
}

each exposure category, the dust mass concentration is assumed to take the maximum value. By that approach, the upper limits of human exposure and received lung dose to Saharan dust particles can be derived. In Table 3, the number of days that correspond to each exposure category is presented (the boundaries of each exposure level, as defined by the percentiles, are shown in the parentheses). As expected, the percentiles of dust concentration exhibit their highest values at Heraklion, while the lowest percentiles are noticed for the town of Volos.

Based on the different exposure categories, we assess the lung dose for residents of the Greek urban sites due to Saharan dust transport throughout a year. However, the foursize SKIRON version used in the present analysis could not provide a detailed particle size distribution, as required by the dosimetry model. Thus, for the description of the size distribution of the dust transported cloud in the Greek area, we employed the long-range transport mode proposed by Schulz et al. (1998) and tested by Zender et al. (2003). More specifically, the dust particle size distribution follows a lognormal form with mass median diameter $(M M D)$ equal to $2.524 \mu \mathrm{m}$ and geometric standard deviation equal to $\sigma=2$. For the mineral aerosol, the particle density $\rho_{p}$ is taken equal to $2.65 \mathrm{~g} \mathrm{~cm}^{-3}$. Note that, a lognormal distribution is fully described by the parameters $M M D, \sigma$ and mass concentration $m$. The long-range transport mode that was used for the present calculations appears to coincide with the "coarse 2" mode derived from the analysis of Gerasopoulos et al. (2007). The latter authors studied the seasonal 
Table 3. Percentiles of the dust mass concentration for the Greek sites (Heraklion, Athens suburb, Patra, Volos) and number of days per year that corresponds to each exposure category.

\begin{tabular}{cccccc}
\hline & & \multicolumn{4}{c}{ Mass concentration $\left(\mu \mathrm{g} \mathrm{m}^{-3}\right)$} \\
\hline Percentile & no. of days per year & Heraklion & Athens suburb & Patra & Volos \\
$90 \%$ & $308(0-90)$ & 20.6 & 11.8 & 12.7 & 8.9 \\
$95 \%$ & $37(90-95)$ & 33.2 & 24.6 & 23.8 & 21.7 \\
$99.5 \%$ & $18(95-99.5)$ & 136.7 & 81.7 & 102.6 & 65.9 \\
$100 \%$ & $2(99.5-100)$ & 257.7 & 155.5 & 177.9 & 140.9 \\
\hline
\end{tabular}

Table 4. Ratio of the deposited mass over the total inhaled mass.

\begin{tabular}{cc}
\hline $\begin{array}{c}\text { Respiratory tract } \\
\text { regions }\end{array}$ & $\begin{array}{c}\text { Mass deposited } \\
\text { fraction }\end{array}$ \\
\hline ET & 0.64 \\
TB & 0.16 \\
AI & 0.10 \\
Total & 0.90 \\
\hline
\end{tabular}

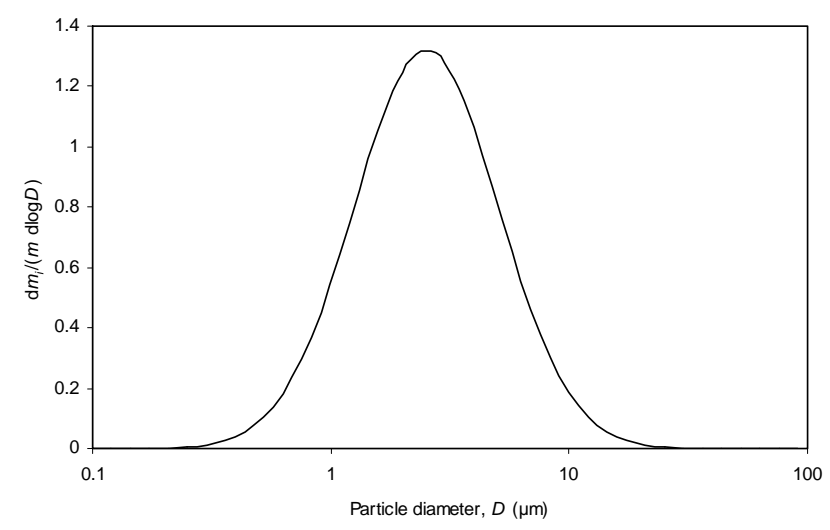

mass size distributions at a coastal site situated $70 \mathrm{~km}$ eastnortheast of Heraklion (Finokalia). For the spring period, enhanced concentration for particles with aerodynamic diameters 3-7 $\mu \mathrm{m}$ (physical diameters 1.8-4.3 $\mu \mathrm{m}$ ) was obtained, attributed to dust transport from Northern Africa. The normalized particle mass distribution (particle mass distribution divided to mass concentration) with the physical characteristics $(M M D, \sigma)$ used for the dosimetric calculations are illustrated in Fig. 5, as a function of particle diameter $D$. However, it should be noted that long-range transported particle sizes measured away from source regions may depend significantly on the distance from the source regions (Park and Kim, 2006). Larger particles can be detected at regions near the source points. The mode of the particle size distribution appears shifted towards smaller particle diameters, as the distance from the dust sources increases. Therefore, the aerosol size distribution used for the depiction of suspended particles at the more distant sites (Athens suburb, Patra, Volos) may be distorted. Aerosol deposition at the various regions of the respiratory tract is strongly dependent on particle size distribution of the inhaled aerosols (Lippmann et al., 1980). Thus, the incorporation of a more detailed bin method in SKIRON modelling system would lead to more accurate dosimetric calculations. However, the use of the current model is considered as efficient for a generic dose assessment.

Fig. 5. Normalized mass distribution as a function of particle diameter for the Greek sites.

In SKIRON modelling system, the atmospheric dust behaves as an inert chemical substance. Therefore, in the present study, mineral dust is considered as non-hygroscopic as is at its native state. However, dust particles may become hygroscopic through the "aging" process - chemical alterations at the particle surface (Zhang et al., 1994; Levin et al., 1996). Moreover, the presence of hygroscopic biological aerosols (i.e. bacteria, pollen) in the atmosphere (Möhler et al., 2007) is often linked to dust transport (Shinn et al., 2003). Particle deposition pattern along the human lung is highly dependent on aerosol hygroscopicity; thus, the forecast model would be significantly improved by taking into account the physicochemical properties of the dust particles in a forthcoming study. Nevertheless, the assumption of inert dust particles, as commonly adopted by the models that deal with dust transport (e.g. Nickovic et al., 2001, and references therein), is applied for the current dosimetric calculations.

The ratio of the deposited mass over the total inhaled mass is presented in Table 4 for the different regions of the human respiratory tract (extrathoracic - ET, tracheobronchial - TB, alveolar - AI) and for one breathing cycle. The calculated values of the deposited fraction show that most of the PM mass stays in the upper respiratory system, namely 

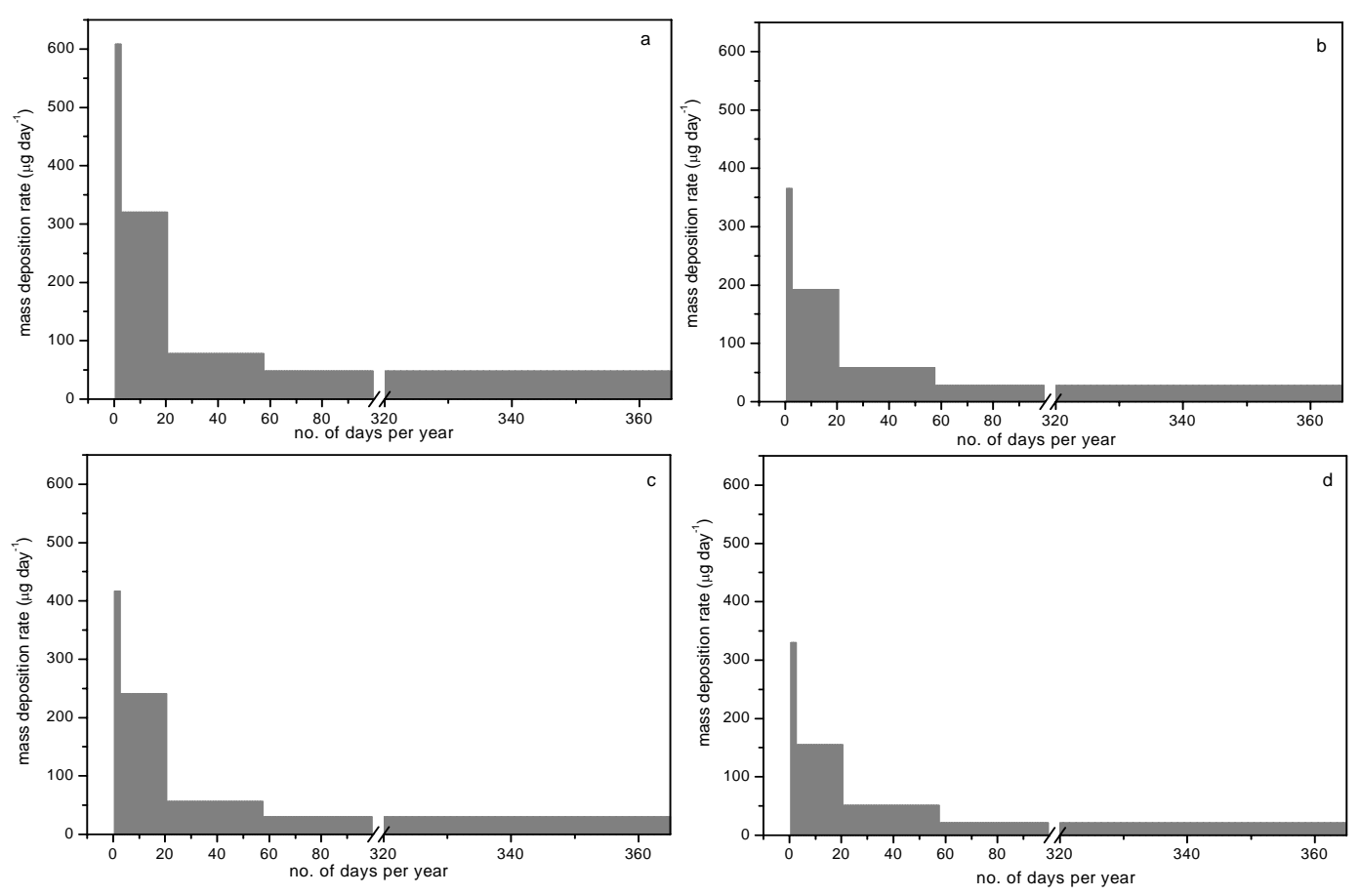

Fig. 6. Mass deposition rates in the human lung as a function of number of days per year for a resident of (a) Heraklion, (b) Athens suburb, (c) Patra and (d) Volos.

the ET region. The deeper lung regions (AI) have a lower concentration of the larger inhaled particles as a result of the deposition made at the entrance of the respiratory tract (ET region). The great amount of PM mass is accumulated at the larger particle sizes, thus the airborne particle mass decreases while traversing the lung. As a consequence, only $10 \%$ of the inhaled particle mass is deposited in the pulmonary lung (AI region).

In order to obtain an integrated assessment of the received inhaled dose from Saharan dust to the residents of the Greek urban areas, the daily mass deposition rates in the lung (TB and AI regions) were calculated for the different exposure conditions throughout a year (Fig. 6), assuming a typical daily exposure of $6 \mathrm{~h}$. Extremely high mass deposited values during a day are performed for the days of severe dust episodes (99.5th-100th percentile), reaching up to $600 \mu \mathrm{g} \mathrm{day}^{-1}$ for a resident at Heraklion. On the other hand, the dust mass deposited in the lung for a resident at Volos is only half under all exposure conditions examined here. It must be noted, that the relationship between inhaled dose and dust concentration is linear, since identical physical activity (light exercise) was assumed for all exposure conditions and at the various sites (see Eq. 1). The calculated mass deposition rates are compared to the respective deposition rates presented in the work of Venkataraman and Raymond (1998), so as to interpret the present results. The latter authors reported that the lung dose resulting from the typical daily exposure in the polluted Los Angeles basin equals to $294 \mu \mathrm{g} \mathrm{day}^{-1}$, while 16-h exposure to environmental tobacco smoke (ETS) leads to dose ranging from 135 to $187 \mu \mathrm{g} \mathrm{day}^{-1}$ for adult males and from 76 to $106 \mu \mathrm{g} \mathrm{day}^{-1}$ for females. Thus, the received lung dose for a resident in Patra or Heraklion town during a moderate dust episode (95th-99.5th percentile) is similar to the dose received after exposure in the polluted urban air basin of Los Angeles. Under low dust exposure conditions (90th-95th percentile), the equivalent doses may approach the particle respiratory deposition in a smoking area.

We have not addressed the toxicological significance of this inhaled dose resulting from the exposure in mineral dust particles, if any. The current calculations showed, however, that the respiratory dose resulting from dust exposure could be significant, generating further studies in this direction.

\section{Conclusions}

In the present study, an attempt was made to determine the mineral dust levels in Greek urban areas and the received inhaled dose. The quantification of the dust transport effects in urban air quality was accomplished by analyzing a large database of $\mathrm{PM}_{10}$ daily measurements and SKIRON model predictions. The analysis confirmed that the dust transport effect reaches its peak during the transition spring and autumn periods, as has already been noticed in previous studies. The concentration of mineral dust particles decreases in general from South to North, due to particle deposition 
mechanisms, thus, the fraction of dust to $\mathrm{PM}_{10}$ concentration appeared to vary significantly depending on the location, of course with respect to the most often followed transport paths. Natural dust transport may contribute by much more than $20 \%$ to the annual number of exceedances (in some cases around $60 \%$ ). The mean annual dust contribution to daily-averaged $\mathrm{PM}_{10}$ concentrations was often found to be greater than $10 \%$ throughout the years examined. However, the poor correlation found in some cases between observed $\mathrm{PM}_{10}$ and simulated dust concentration values could be attributed to various reasons, such as specific geomorphological characteristics of the different areas, northerly etesian winds during summer that reduce dust transport, as well as limitations of the atmospheric/dust transport model (identification of dust sources, relatively low horizontal resolution).

The determination of the received inhaled doses by the residents in the Greek urban areas showed that the inhaled dose was greater in the upper respiratory system (extrathoracic region), since the major amount of PM mass is accumulated at the larger particle sizes that are mostly deposited before reaching the lung. Higher lung deposition rates were calculated for the citizens of the southern part of the country (Heraklion), while the doses are reduced by half for an individual living $400 \mathrm{~km}$ far to the North. The calculated lung doses during severe and moderate dust episodes were found to be comparable to those received during exposure in polluted urban and smoking areas.

These concluding remarks are also applicable to most southern European urban areas, since dust episodes and local weather conditions are similar to the Greek ones. However, the above results cannot be extrapolated to northern African areas, where the situation is expected to be even worst due to the higher dust concentrations and the frequency of extreme desert dust events.

Acknowledgements. This work has been supported by the European Union 6th Framework Program CIRCE IP, contract \#036961. The authors also acknowledge the Greek Ministry of Environment City Planning and Public Works for providing the data on $\mathrm{PM}_{10}$ mass concentration from their monitoring network. The anonymous reviewers are acknowledged for their useful and constructive comments.

Edited by: N. Mihalopoulos

\section{References}

Astitha, M., Kallos, G., and Katsafados, P.: Air pollution modelling in the Mediterranean Region: Analysis and forecasting of episodes, Atmos. Res., 89, 358-364, 2008.

Charlson, R. J., Langner, J., Rodhe, H., Leovy, C. B., and Warren, S. G.: Perturbation of the Northern Hemisphere radiative balance by backscattering from anthropogenic sulfate aerosols, Tellus AB, 43, 152-163, 1991.

Dockery, D. W. and Pope, C. A.: Acute respiratory effects of particulate air pollution, Annu. Rev. Publ. Health, 15, 107-132, 1994.
Escudero, M., Querol, X., Pey, J., Alastuey, A., Pérez, N., Ferreira, F., Alonso, S., Rodríguez, S., and Cuevas, E.: A methodology for the quantification of the net African dust load in air quality monitoring networks, Atmos. Environ., 41, 5516-5524, 2007.

Gerasopoulos, E., Kouvarakis, G., Babasakalis, P., Vrekoussis, M., Putaud, J. P., and Mihalopoulos, N.: Origin and variability of particulate matter $\left(\mathrm{PM}_{10}\right)$ mass concentrations over the Eastern Mediterranean, Atmos. Environ., 40, 4679-4690, 2006.

Gerasopoulos, E., Koulouri, E., Kalivitis, N., Kouvarakis, G., Saarikoski, S., Mäkelä, T., Hillamo, R., and Mihalopoulos, N.: Size-segregated mass distributions of aerosols over Eastern Mediterranean: seasonal variability and comparison with AERONET columnar size-distributions, Atmos. Chem. Phys., 7, 2551-2561, 2007, http://www.atmos-chem-phys.net/7/2551/2007/.

Herut, B., Nimmo, M., Medway, A., Chester, R., and Krom, M. D.: Dry atmospheric inputs of trace metals at the Mediterranean coast of Israel (SE Mediterranean): Sources and fluxes, Atmos. Environ., 35, 803-813, 2001.

International Commission on Radiological Protection (ICRP): $\mathrm{Hu}-$ man Respiratory Tract Model for Radiological Protection. Technical report, ICRP publication 66, 1994.

Janjic, Z.: The step-mountain eta coordinate model: Further developments of the convection, viscous sublayer and turbulence closure schemes, Mon. Weather Rev., 122, 927-945, doi:10.1175/1250-0493, 1994.

Janjic, Z. I., Gerrity, J. P., and Nickovic, S.: An alternative approach to nonhydrostatic modelling, Mon. Weather Rev., 129, 1164-1178, doi:10.1175/1520-0493, 2001.

Kallos, G., Kassomenos, P., and Pielke, R. A.: Synoptic and mesoscale weather conditions during air pollution episodes in Athens, Greece, Bound.-Lay. Meteorol., 62, 163-184, 1993.

Kallos, G., Nickovic, S., Papadopoulos, A., Jovic, D., Kakaliagou, O., Misirlis, N., Boukas, L., Mimikou, N., Sakellaridis, G., Papageorgiou, J., Anadranistakis, E., and Manousakis, M.: The regional weather forecasting system SKIRON: An overview, International Symposium on Regional Weather Prediction on Parallel Computer Environments, Athens, Greece, 15-17 October, 1997.

Kallos, G., Papadopoulos, A., Katsafados, P., and Nickovic, S.: Transatlantic Saharan dust transport: Model simulation and results, J. Geophys. Res., 111, D09204, doi:10.1029/2005JD006207, 2006.

Kallos, G., Spyrou, C., Papantoniou, N., Mitsakou, C., Astitha, M., Solomos, S., and Katsafados, P.: Analysis of the Particulate Matter Exceedances in Greece, Period 2001-2004, Final Report Prepared for the Ministry of Environment City Planning and Public Work, June 2007a.

Kallos, G., Astitha, M., Katsafados, P., and Spyrou, C.: Long-range transport of anthropogenically and naturally produced particulate matter in the Mediterranean and North Atlantic: current state of knowledge, J. Appl. Meteorol. Clim., 46, 1230-1251, $2007 \mathrm{~b}$.

Kishcha, P., Alpert, P., Shtivelman, A., Krichak, S. O., Joseph, J. H., Kallos, G., Katsafados, P., Spyrou, C., Gobbi, G. P., Barnaba, F., Nickovic, S., Pérez, C., and Baldasano, J. M.: Forecast errors in dust vertical distributions over Rome (Italy): Multiple particle size representation and cloud contributions, J. Geophys Res., 112, D15205, doi:10.1029/2006JD007427, 2007.

Koçak, M., Mihalopoulos, N., and Kubilay, N.: Contributions of natural sources to high $\mathrm{PM}_{10}$ and $\mathrm{PM}_{2.5}$ events in the eastern 
Mediterranean, Atmos. Environ., 41, 3806-3818, 2007.

Levin, Z., Ganor, E., and Gladstein, V.: The effects of desert particles coated with sulfate on rain formation in the eastern Mediterranean, J. Appl. Meteorol., 35, 1511-1523, 1996.

Lippmann, M., Yeates, D. B., and Albert, R. E.: Deposition, retention and clearance of inhaled particles, Brit. J. Ind. Med., 37, 337-362, doi:10.1136/oem.37.4.337, 1980.

Mesinger, F., Janjic, Z. I., Nickovic, S., Gavrilov, D., and Deaven, D. G.: The step-mountain coordinate: Model description and performance for cases of Alpine lee cyclogenesis and for a case of an Appalachian redevelopment, Mon. Weather Rev., 116, 1493-1518, doi:10.1175/1520-0493, 1988.

Mitsakou, C., Helmis, C., and Housiadas, C.: Eulerian modelling of lung deposition with sectional representation of aerosol dynamics, J. Aerosol Sci., 36, 75-94, doi:10.1016/jaerosci.2004.08.008, 2005.

Möhler, O., DeMott, P. J., Vali, G., and Levin, Z.: Microbiology and atmospheric processes: the role of biological particles in cloud physics, Biogeosciences, 4, 1059-1071, 2007, http://www.biogeosciences.net/4/1059/2007/.

Nickovic, S., Kallos, G., Papadopoulos, A., and Kakaliagou, O.: A model for prediction of desert dust cycle in the atmosphere, J. Geophys. Res., 106(D16), 18 113-18 129, 2001.

Papadopoulos, A., Katsafados, P., Kallos, G., and Nickovic, S.: The weather forecasting system for Poseidon - an overview, Global Atmosphere and Ocean System, 8, 219-237, 2002.

Papayannis, A., Amiridis, V., Mona, L., Tsaknakis, G., Balis, D., Bösenberg, J., Chaikovski, A., De Tomasi, F., Grigorov, I., Mattis, I., Mitev, V., Müller, D., Nickovic, S., Pérez, C., Pietruczuk, A., Pisani, G., Ravetta, F., Rizi, V., Sicard, M., Trickl, T., Wiegner, M., Gerding, M., Mamouri, R. E., D’Amico, G., and Pappalardo, G.: Systematic lidar observations of Saharan dust over Europe in the frame of EARLINET, J. Geophys. Res., 113, (D10204), doi:10.1029/2007JD009028, 2008.

Park, S. U. and Kim, J. W.: Aerosol size distributions observed at the Seoul National University campus in Korea during the Asian dust and non-Asian dust periods, Atmos. Environ., 40, 17221730, 2006.

Perrino, C., Canepari, S., Cardarelli, E., Catrambone, M., and Sargolini, T.: Inorganic constituents of urban air pollution in the Lazio region (Central Italy), Environ. Monit. Assess., 136, 6986, 2008.

Querol, X., Alastuey, A., Rodríguez, S., Plana, F., Ruiz, C. R., Cots, N., Massagué, G., and Puig, O.: $\mathrm{PM}_{10}$ and $\mathrm{PM}_{2.5}$ source apportionment in the Barcelona Metropolitan area, Catalonia, Spain, Atmos. Environ., 35, 6407-6419, 2001.
Querol, X., Alastuey, A., Ruiz, C. R., Artinano, B., Hansson, H. C., Harrison, R. M., Buringh, E., Ten Brink, H. M., Lutz, M., Bruckmann, P., Straehl, P., and Schneider, J.: Speciation and origin of $\mathrm{PM}_{10}$ and $\mathrm{PM}_{2.5}$ in selected European cities, Atmos. Environ., 38, 6547-6555, 2004.

Rodríguez, S., Querol, X., Alastuey, A., Kallos, G., Kakaliagou, O.: Saharan dust contributions to PM10 and TSP levels in Southern and Eastern Spain, Atmos. Environ., 35, 2433-2447, 2001.

Rodríguez, S., Querol, X., Alastuey, A., Viana, M. M., and Mantilla, E.: Events affecting levels and seasonal evolution of airborne particulate matter concentrations in the Western Mediterranean, Environ. Sci. Technol., 37, 216-222, 2003.

Schulz, M., Balkanski, Y. J., Guelle, W., and Dulac, F.: Role of aerosol size distribution and source location in a threedimensional simulation of a Saharan dust episode tested against satellite-derived optical thickness, J. Geophys. Res., 103, 10 579-10 592, 1998.

Shinn, E. A., Griffin, D. W., and Seba, D. B.: Atmospheric transport of mold spores in clouds of desert dust, Arch. Environ. Health, 58, 498-504, 2003.

Sunnu, A., Afet, G., and Resch, F.: A long-term experimental stydy of the Saharan dust presence in West Africa, Atmos. Environ., 87, 13-26, 2008.

Tegen, I. and Fung, I.: Modelling of mineral dust in the atmosphere: Sources, transport and optical thickness, J. Geophys. Res., 99, 22 897-22 914, 1994.

Zender, C. S., Bian, H., and Newman, D.: Mineral dust entrainment and deposition (DEAD) model: Description and 1990s dust climatology, J. Geophys. Res., 108, 4416, doi:10.1029/2002JD002775, 2003.

Zhang, Y., Sunwoo, Y., Carmichael, G. R., and Kotamarthi, V.: Photochemical processes in the presence of dust: An evaluation of the effect of dust on particulate nitrate and ozone formation, J. Appl. Meteorol., 33, 813-824, 1994.

Venkataraman, C. and Raymond, J.: Estimating the lung deposition of particulate polycyclic aromatic hydrocarbons associated with multimodal urban aerosols, Inhal. Toxicol., 10, 183-204, 1998.

Viana, M., Pérez, C., Querol, X., Alastuey, A., Nockovic, S., and Baldasano, J. M.: Spatial and temporal variability of PM levels and composition in a complex summer atmospheric scenario in Barcelona (NE Spain), Atmos. Environ., 39, 5343-5361, 2005.

Weibel, E. R. Morphometry of human lungs, Springer Edition, Berlin, Germany, 136-143, 1963.

Yu, S., Zender, C. S., and Saxena, V. K.: Direct radiative forcing and atmospheric absorption by boundary layer aerosols in the southeastern US: Model estimates on the basis of new observations, Atmos. Environ., 35, 3967-3977, 2001. 